\title{
Information Privilege Outreach for Undergraduate Students
}

\author{
Sarah Hare and Cara Evanson
}

\begin{abstract}
Through their affiliation with an institution of higher education, undergraduate students are able to access a range of research materials and, as a result, enter the scholarly conversation and build upon existing research. This ability to access information that others cannot is called information privilege. This article builds upon Char Booth's work on information privilege to present library outreach as a way to raise awareness about the disparity in information access and to encourage students to consider how their own scholarship and sharing practices impact others. The article presents one approach for facilitating information privilege outreach with undergraduate students.
\end{abstract}

\section{Introduction}

When compared to those who are not affiliated with institutions of higher education, undergraduate students learn and conduct research with increased access to research material, including journal articles, data, and primary sources. This access to research material, often combined with access to additional research support, faculty, and a peer network, affords college students opportunities that others may not have, including the opportunity to build upon existing research and enter the scholarly conversation. The affordance or opportunity to access information that others cannot is called information privilege.

The Framework for Information Literacy for Higher Education (hereafter, Framework) specifically mentions information privilege in the "Information Has Value" frame. The last disposition in this frame states that learners "are inclined to examine their own information privilege." ${ }^{\prime 1}$ As a foundational document for information literacy instruction, the inclusion of information privilege within the Framework legitimizes its role within information literacy. It is notable, however, that the document does not provide a definition of this term. Additionally, the Framework does not offer any guidance on how to teach students about information privilege as a concept or how to help students grasp that not everyone enjoys the same level of information access.

This article aims to fill that gap. While information privilege can exist outside of academia, this article focuses specifically on the information privilege that stems from affiliation with an institution of higher education in the United States. Limiting our

* Sarah Hare is Scholarly Communication Librarian in Herman B. Wells Library at Indiana University; e-mail: scrissin@indiana.edu. Cara Evanson is Information Literacy Librarian at E.H. Little Library in Davidson, North Carolina; e-mail: caevanson@davidson.edu.C2018 Sarah Hare and Cara Evanson, Attribution-NonCommercial (http://creativecommons.org/licenses/by-nc/4.0/) CC BY-NC. 
scope to this type of information privilege enables us to explore how access to research affects our students' lives before and after graduation.

We recognize that information privilege is a term that carries assumptions about who has power, who does not, and what types of information are valuable. We use the term "information privilege" because it provides a relevant framework for talking to students about their temporarily increased level of information access. We also believe that framing students' information access as a privilege underscores responsibility. Calling the concept a privilege signals to both students and instructors that they have a relative advantage over others and, more important, a responsibility to acknowledge and use their privilege to challenge the current information access disparity, possibly by making their own work open. Information privilege is also connected to critical information literacy, as it "recognizes the complicity of the individual - and the individual as a community member-in information-based power structures and struggles." 2

Information privilege outreach, then, is focused on raising awareness about the disparity in information access and the subsequent importance of open access publishing. We define outreach to include formal and informal student education via workshops, instruction sessions, programming, consultations, and any other interaction that librarians may have with students or instructors. While information privilege outreach can differ depending on context, one core tenet of this type of outreach is that undergraduate students' work is worth sharing openly, if they so choose.

As librarians, it is professionally responsible and ethically imperative to raise undergraduate student awareness about the disparity in information access. Indeed, students must understand the systemic issues that create information privilege to become ethical and informed participants in our 21st-century information landscape. This article will describe an approach used to educate students at Davidson College about the concept of information privilege while empowering them to reflect on, consider, and question how their own information privilege impacts others.

\section{Literature Review}

The concept of information privilege and the act of information privilege outreach is rooted in critical information literacy. Annie Downey notes that, while the "theory of critical information literacy is still being constructed and there is no fully developed and agreed upon definition," "librarians typically use one of three approaches to teach critical information literacy: creating a student-centered environment, dialogue, and problem-posing methods." ${ }^{\prime 4}$ Information privilege outreach can, and often does, provide a space for all three of these strategies by empowering students to see themselves as agents of change, prompting discussion and reflection on how open access or closed scholarship impacts others, and posing questions to students about how they would like to share (or not share) their own work.

Critical information literacy presents an alternative to what Paulo Freire calls the "banking model" of education, ${ }^{5}$ which James Elmborg has described as students "approach[ing] their education as consumers and passive receivers of knowledge rather than active agents shaping their own lives." model is a pedagogy focused on helping students find what Freire has labeled "critical consciousness." ${ }^{\prime 7}$

Critical consciousness is developed when students learn about the problems in the world, particularly oppression and inequality, and their role and agency in affecting these problems. ${ }^{8}$ Lack of access to information is a real and tangible problem for many. Information privilege outreach facilitates students' questioning of why information privilege is a reality and what their own role in that inequality may be. In short, the central goal of information privilege outreach is to help students 
identify and "act upon the power structures underpinning information's production and dissemination."

Finally, information privilege outreach recognizes that, as Christine Pawley has stated, "information 'access' is not just about information consumerism but also about individuals and groups of people actively shaping their world as knowledge producers in a way that renders the consumer-producer dichotomy irrelevant." ${ }^{10}$ Information access is not disconnected from power and privilege; rather, they are inextricably linked. Information privilege seeks to make this connection visible.

The connection between critical information literacy and information privilege is also visible in Char Booth's work. Booth first coined the specific term "information privilege" in a 2013 blog post. ${ }^{11}$ In the post, titled "open access as pedagogy," Booth advocates for turning the "banking' model of higher education on its head"12 and identifies critical and feminist pedagogy as a basis for educational opportunities with undergraduate students around issues of openness. ${ }^{13}$ In a subsequent blog post, "on information privilege, ${ }^{\prime 14}$ Booth explicitly connects information privilege and critical information literacy. Booth states that "in practice [information privilege] is the most effective framework I have identified to engage learners and collaborators with a wide range of skills and perspectives that constitute (critical) information literacy."15

Beyond these two blog posts, Booth has written or spoken about information privilege several ${ }^{16}$ times. ${ }^{*}$ Booth's work predominantly highlights what information privilege outreach can look like in the classroom. Examples from Booth's own teaching include dialoguing with students about the cost of library materials, ${ }^{17}$ working with students to expand Wikipedia stubs, ${ }^{18}$ and encouraging students to make their work open by sharing it in an institutional repository. ${ }^{19}$

Although it has been several years since Booth first coined "information privilege" and wrote the first blog post about information privilege outreach, and even though the term is included in the Framework, there are still very few examples in the literature of how to do information privilege outreach or education. Moreover, there is still some ambiguity on the definition of information privilege, and there are no professional guidelines or best practices for helping students reflect on their own information privilege.

\section{Information Privilege and Undergraduate Students}

Roger Schonfeld states that commencement "signals a moment where thousands of authorized users of licensed e-resources lose access." ${ }^{20}$ Students' loss of information access at graduation is one result of the traditional scholarly communication system. Because scholarship that is rewarded through tenure and promotion is often paywalled or expensive to access for institutions and individuals, the level of information access that students experience in college may not be an accurate reflection of the access they will have after graduation.

When librarians fail to acknowledge graduating students' change in information access, it can affect students' lives as alumni. In 2016, Project Information Literacy published a report on how recent graduates interact with and use information. More than 1,600 graduates were surveyed, 50 percent of whom reported frustration with the loss of access to information resources at their alma mater, including campus library databases. ${ }^{21}$ In addition, 73 percent reported difficulty with locating affordable sources after graduation. ${ }^{22}$ If we, as librarians, fail to raise awareness about students' change in access, they will continue to be unprepared for it.

* Booth has also given keynotes on information privilege at WILU 2015 and the Northwest Interlibrary Loan and Resource Sharing Conference 2016. Neither the conferences nor Booth have made recordings or slide notes available for these presentations, so these could not be taken into account for this literature review. 
Many students will also become alumni who produce information. While not every student will become a scholar, students might blog, write code, or share creative projects after graduation. One goal of information privilege outreach is to empower students to see their output, regardless of what it is, as worth sharing. Another goal is to make visible the connection between their own impending loss of access and how individual decision-making relates to open access practices. Once students understand how the collective impact of individual author choices affects their own loss of access at graduation, they can better understand how their choices regarding own work, however small, have significance and broader implications for the information access of others.

Beyond recognizing the impact of sharing practices for individuals, information privilege outreach provides a space to ask students to interrogate the systems that reward closed scholarship. For this reason, in addition to introducing open access publishing and encouraging students to make intentional choices about how they share their work, information privilege outreach is an opportunity to encourage students to question the practices that shape the academy. It is not enough to introduce open access; librarians need to do a deeper dive into the why behind the disparity in information access.

Thus, outreach can raise students' awareness about the disparity in information access while also describing the complex reasons why such a disparity even exists. While information privilege discussions often surface issues with tenure and promotion, the flaws of traditional peer review, or the pervasive use of journal metrics as the primary indicator of rigor and reputation, it is beyond the scope of this article to address these issues in detail. However, the Framework provides a useful primer for explaining complex scholarly communication concepts and academic authority to undergraduate students (see the discussion of "packaging" authoritative content and last two dispositions for the "Authority is Constructed and Contextual" frame, for example). ${ }^{23}$

In addition to educating students, information privilege outreach could have an impact on the broader scholarly communication system. The ACRL Intersections of Scholarly Communication and Information Literacy white paper states that encouraging students to consider openness for their own work can influence them to become "advocates for changing the broader system, by, for example, passing student and faculty open access resolutions, and supporting legislation." ${ }^{24}$ Recognizing that students' scholarship is worth sharing legitimizes undergraduate students' output and acknowledges their current and potential future role in transforming the scholarly communication system. By doing this, we as librarians empower everyone to play a role in information creation instead of "privileg[ing] faculty control over the production of knowledge." 25

\section{The Importance of Reflection}

We believe that information privilege outreach is most transformative when students are asked to reflect on their own power and privilege. In this article, we define reflection as intentional introspection, questioning, and consideration of a specific concept or issue. Reflection includes students participating in internal, individual examination as well as students "explor[ing] [their] underlying assumptions in dialogue" with their peers. ${ }^{26}$ In addition to asking students to intentionally debrief, the goal of reflection is to push students to think structurally about information privilege and consider the complex processes involved in facilitating their access to information.

In "Information Literacy and Reflective Pedagogical Praxis," Heidi Jacobs holds that critical information literacy practitioners should "facilitate problem posing" with students and "encourage them to find problems related to themselves in the world and with the world so that they will feel increasingly challenged and obliged to respond to those very real challenges." 27 Problem posing in an information privilege outreach setting 
includes asking students questions that prompt reflection, including, "How do you use proprietary information in your life and research now?" "How might a lack of access affect you as an alum?" "How might you change your research practices to read, cite, and engage with marginalized voices?" and "What role should you have, as someone who is an information creator and currently has abundant access, in changing the current scholarly communication system?" These questions can transform information privilege outreach from a worn lecture on the cost of information to an engaging conceptual exercise that helps students understand how these issues affect them and others directly.

\section{Background}

Davidson College is a private, undergraduate liberal arts institution with 1,950 students in the Charlotte, North Carolina area. Though the college continues to recruit a more diverse student body, 67 percent of Davidson students identified as white in 2016. ${ }^{28}$ Through the Davidson Trust, ${ }^{29}$ the college has made a commitment to make Davidson more accessible by meeting all accepted students' demonstrated need without packaged loans. As a result of this initiative, students continue to represent a variety of socioeconomic backgrounds. While Davidson is certainly a place of privilege, working with undergraduate students from a range of experiences and backgrounds created a unique setting to discuss the concept of information privilege.

Though on average more than 80 percent of students at Davidson eventually go on to earn graduate or professional degrees ${ }^{30}$ and may regain information access at that point, only 17.5 percent of students in the class of 2015 were enrolled in graduate school or other specialized postgraduate training six months after graduation. ${ }^{31}$ Although some graduates who opt not to attend graduate school immediately may gain access to proprietary information through their employers, others will likely experience a temporary disruption in access as soon as their Davidson affiliation ends.

While attending graduate school is not a necessity or even a desire for all students, lack of institutional access to information during this gap of time can present a real obstacle. Project Information Literacy's 2016 report noted that "more than anything else, [75 percent of] graduates sought how-to information [for] urgent problems in their personal lives... [including] how to make household repairs... or how to read a legal agreement." ${ }^{32}$ Other recent graduate information needs include accessing library resources to find answers to health questions, ${ }^{33}$ identifying best practices for money management, ${ }^{34}$ and locating professional development and career guidance. ${ }^{35}$ While these information needs may seem trivial at first glance, these are inquiries that could affect graduates' livelihood, success, or health.

In addition, Davidson students frequently publish scholarly book chapters and articles, even as undergraduates. This is encouraged by the college, as the Davidson website states, "faculty members...encourage students to join them in extensive exploration of original work...[and] contribute to the growing body of knowledge in a wide variety of fields." 36 After publication, students sometimes come to the library to request access to their own work after they have signed away their exclusive rights as authors or coauthors and can no longer access the full text of their book chapters or articles themselves.

For example, in July 2015, a recent Davidson graduate reached out to us. The student had published his first peer-reviewed article a few months prior and was interested in continuing his research. He had future plans to attend graduate school but would not be attending in the coming year. He expressed curiosity about when he would lose access to Davidson's databases, and we had to inform him that he would lose access in just a few weeks - as soon as his summer employment with the college ended. This student's inquiry was not unique. It was a question the library had fielded before, and 
we continue to receive requests of this nature from alumni and graduating seniors. This specific experience motivated the creation of outreach opportunities on how students' information access would change after graduation.

\section{Information Privilege Assessment at Davidson College}

In 2015, we also performed an assessment that confirmed that our students harbored misconceptions about information access. This assessment was part of a library minicourse all incoming first-year students are required to complete. Students were asked to read several case studies describing hypothetical researchers and respond to two of them, noting assumptions the researchers made and the opportunities they missed. One of the case studies describes a video blogger (vlogger) who finds a useful article but decides to investigate other sources after he discovers that he will have to pay to access it. The case study does not state why the vlogger declines to pursue the source or even offer an explanation of why the source costs money.

Students' reactions to this detail of the case study were surprising. Of the $510 \mathrm{stu}-$ dents who took the assessment, 329 students discussed the vlogger in their response. One hundred and twenty-six of these respondents (38\%) discussed payment, money, or the cost of information in some way. Thirty-eight students, or about 11 percent of those who discussed the vlogger, explicitly labeled the vlogger's failure to access the article as a negative personal choice. Many of these students criticized the vlogger for his failure to obtain the best source possible for his research, writing that the vlogger was "not willing to pay to access the most relevant information" and "instead of paying a small fee to ensure he had trustworthy information that he could safely distribute, the Vlogger tried to fit information into his argument that didn't exactly go along with what he was going to vlog about."

Four students outright called the vlogger lazy, and one student even urged the vlogger to "man up and pay the fee." This illustrated that some of our students' misconceptions were intimately tied to their own economic privilege and underlying assumption that everyone could always afford to purchase information.

In addition, some students harbored basic misconceptions about library access, information paywalls, and credibility. For example, a few students critiqued the vlogger for not knowing that the article was probably available freely through Google Scholar or another website. ${ }^{37}$ Other students assumed that everyone had the ability to search library databases or access library resources in print. Interestingly, a few students even praised the vlogger for not paying for the article, as they believed that a source that costs money could not be credible.

We saw this as a call to action; we knew that it was imperative to address students' fundamental misconceptions about information access. While many incoming students had presumably accessed proprietary content, possibly with the assistance of a librarian, it seemed apparent that they had never learned about the why behind information access. Our analyses of student responses did much more than shape our programming. Every information privilege outreach activity incorporated quotes from the assessment and pushed students to consider why misconceptions about information access could be harmful.

\section{Information Privilege Outreach}

We created and facilitated three information privilege events during the 2015-2016 academic year. Each event was cocurricular and the result of a collaboration with another department on campus. Each of the three events had a different audience, so we tailored each event to that audience's specific concerns and interests. The hope was that our cocurricular approach would eventually inspire more in-depth 
conversations about information access in the classroom and in one-on-one student consultations.

First, we created and delivered a panel presentation on the ethics of information access for Open Access Week 2015, which asked audience members to consider how their own access to information influenced their judgments of others using illegal means to access research. Next, we collaborated with Davidson's Center for Career Development to deliver a workshop for seniors entitled “Why You Won't Have JSTOR When You Graduate and What You Can Do about It." The session informed students of their upcoming loss of information access and introduced free information sources that they could use after graduation. Finally, we created an information privilege booth for Davidson's QuestBridge Scholars' Pathways of Privilege event. The booth provided an interactive opportunity for students to consider the repercussions of having little or no information access. The following is an extended discussion of each of these events.

\section{The Ethics of Information Access}

We started building campus awareness about information privilege with a panel on the ethical dimensions of information access in fall 2015. We partnered with Davidson's Vann Center for Ethics for the event, as its goal is to help students consider complex ethical dilemmas. ${ }^{38}$ We invited Kevin Smith, a junior faculty member in the Biology Department, to join us in facilitating the panel discussion and contribute a faculty perspective to the conversation.

The panel began with a conversation about ethics. The first section was dedicated to an overview of problems with the current scholarly publishing system and the connection between information access and social justice. We cited Aaron Swartz's Guerilla Open Access Manifesto ${ }^{39}$ and asked the audience to consider how their own ability to access information influenced their ethical judgments of illegal or "guerilla" open access tactics like the information exchanges that happen through the Twitter hashtag \#icanhazpdf.

Dr. Smith discussed open access from a faculty perspective by articulating the challenges that faculty can face when choosing to publish in an open access journal, particularly when they have not yet attained tenure. We concluded the panel with a discussion of Davidson students' information privilege. To demonstrate the privilege Davidson students experience, we juxtaposed quotes from our 2015 assessment of incoming students' misconceptions about information access with data about library resources and services available to the Davidson College community. This juxtaposition illustrated how ignorance about information privilege can be harmful. The panel concluded with asking audience members what responsibility, if any, the Davidson community had to change the current information access disparity. During the Q\&A period, audience members asked informed questions about the role of professional societies in the open access movement, the perceived quality of open access materials, and the effectiveness of new peer review models, including open peer review.

\section{The Role of Current and Future Information Creators}

At the beginning of the spring 2016 semester, we continued campus conversations with an event aimed at seniors. The session, which was part of our Center for Career Development's annual Senior Summit, was entitled “Why You Won't Have JSTOR When You Graduate and What You Can Do about It." " The hour-long session was both

\footnotetext{
* To see the full recording of the panel "Ethics in Information Access," visit https://youtu.be/ 1TOs-us6eLY [accessed 1 October 2017].

† To see all slides and notes for the presentation portion of this workshop, visit https://www. haikudeck.com/jstor-presentation-education-presentation-684957ec7b [accessed 1 October 2017].
} 
practical and conceptual. Our goal was to give students tools for finding information after graduation while also educating them about the underlying reasons for why they would lose access.

One tool that we created was a resource guide that students could use to find open

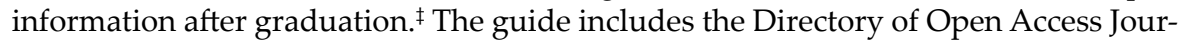
nals, public library information, and links to resources provided by North Carolina's consortial digital content provider, NC LIVE. The goal was to help students cope with the sudden loss of access that they would experience.

We also asked students to reflect on their own role as information creators. We invited students to identify an information output that they had created - whether for school, employment, or creative interests - but had not shared openly, either through simply making the full text publicly accessible or licensing it under a Creative Commons license. $\$$ We then asked students to articulate the benefits and challenges of making that work openly available for anyone to see. After the discussion, we asked students to break into groups based on their interests and then led them through exercises.

The academic exercise ${ }^{\mathbb{I I}}$ asked students to compare a restrictive copyright agreement with a more open agreement to construct language for negotiating with a publisher while using an addendum. We used the SPARC author addendum for this exercise. ${ }^{40}$ The work exercise asked students to read and synthesize a corporate intellectual property agreement to understand what they could and could not do with work that they might produce as an employee or a "work for hire." The creative exercise asked students to learn about Creative Commons licenses and apply them to a creative output to make the work open for others to adapt and build upon.

It is imperative to emphasize again that these exercises were built on the foundational assumption that students' work should be shared, if they so desire. Stephanie Davis-Kahl holds that "[a]sking students to consider if and how they want their own work to be shared and used by others shifts the nature of discussions from cautionary and reactive to reflective and proactive, and explicitly acknowledges that the students' work is valued enough to be shared if they choose." ${ }^{41}$ We agree and as a result, an inherent goal of the session was to encourage students to see their work as legitimate.

\section{The Disparity in Information Access}

Finally, we concluded spring semester 2016 with an information privilege booth where students were given an interactive opportunity to consider the repercussions of having little or no information access. The booth was part of Davidson College's QuestBridge Scholars Pathways of Privilege. QuestBridge is an organization that pairs high-achieving, low-income students with selective colleges and universities across the country. ${ }^{42}$ The QuestBridge scholars at Davidson formed an official campus student organization, and Pathways of Privilege is one of their annual events. The purpose of the event is to raise awareness about various types of privilege, such as food privilege, racial privilege, gender privilege, and passport privilege. The student organizers solicited entries, and we reached out on behalf of the library to propose a booth on information privilege. 2016 was the second year for the Pathways of Privilege event, but it was the first year that the event featured a booth on information privilege.

$\ddagger$ To access the research guide, visit http://davidson.libguides.com/alumni/access [accessed 1 October 2017].

$\S$ A Creative Commons license is an extension of copyright that tells others upfront how their work should be used and re-mixed. For a primer on Creative Commons licenses, see https:// creativecommons.org/share-your-work/licensing-considerations/ [accessed 1 October 2017].

II To access the academic, work, and creative exercises, visit Project CORA at www.projectcora. org/assignment/why-you-won $\%$ E2\%80\%99t-have-jstor-when-you-graduate-and-what-you-cando-about-it [accessed 1 October 2017]. 
At our booth, in addition to viewing institutional journal prices, students could choose to participate in a choose-your-own-adventure scenario* created with Twine. The Twine is designed to mirror the vlogger case study that we asked students to analyze in our 2015 assessment, except that this time the students are making their own information decisions as the vlogger. The premise is that the Twine player is a recent college alum on a tight budget, attempting to research a specific topic for his or her vlog without intuitional access to information. The player runs into numerous obstacles, including article view limits on The New York Times, Google Scholar paywalls, and limited weekend hours at the public library.

Eventually, the players are forced to give up on their research and the Twine routes them to a page that contains a few of the most strongly worded student responses from our 2015 assessment regarding the issue of access. These quotes, which call the vlogger lazy and ignorant, allowed students to experience their classmates' comments firsthand and confront the consequences of ignorance about information privilege. After this exercise, students were able to debrief and reflect with a librarian or one of our student peer research advisors about information privilege. Many students visiting the booth were surprised that they would lose access to Davidson's databases after graduation and astounded by the exorbitant cost of information. Part of the debrief centered around how students' own sharing practices can make an impact.

\section{Summary}

Davidson College's information privilege outreach was exploratory in nature. While we did not systematically assess these three events, we generally found that they were successful and impactful. For example, our partnership with the Vann Center for Ethics and Professor Smith for the OA Week 2015 panel led to subsequent partnerships, including a panel on Sci-Hub and collaborative Open Educational Resource (OER) work. For the "ISTOR" workshop for seniors, we asked students to complete a one-minute paper at the end of the session. Students mostly expressed surprise and encouraged us to introduce loss of access earlier in students' academic career, perhaps freshman or sophomore year. After the information privilege booth, we found a student reflection that mentioned the impact our booth had. ${ }^{43}$ Overall, we concluded that students were generally interested in information privilege as a concept and particularly engaged when considering the openness of their own work. We would invite other institutions to replicate this kind of outreach in their own context in order to eventually develop more robust assessment mechanisms and, as a result, learn more about the effectiveness of information privilege outreach systematically.

\section{Conclusion}

Undergraduate students are our future researchers and scholars. We will not be able to rectify our current scholarly communication system or address the disparity in information access without them. One way to address these issues is to raise students' awareness about information privilege, their own future access, and about how their decisions can affect the information access of others.

The importance of information privilege has been introduced in Booth's scholarship and acknowledged by ACRL through the Framework. While this is a noteworthy start, as a profession we still have a long way to go in providing guidance and support for librarians engaged in information privilege work and in creating learning environments for students that promote reflection. Further, a more robust conversation is needed around the term "information privilege" and the practice of information privilege outreach.

* To play the interactive Twine that we created, visit http://philome.la/SarahCrissinger/finalversion-privilege-table [accessed 1 October 2017]. 
For example, because the term is focused on those who have an advantage, outreach often inherently focuses only on those with power. This kind of outreach risks becoming overly simplistic by presenting openness of student work as a solution to an incredibly complex issue. A larger conversation about terminology and critical practices is needed.

Until we begin to engage students in dialogue about information privilege, we are missing a critical opportunity. As librarians, our time with students is often dedicated to encouraging them to find and use the best possible information available, while almost no time is devoted to why they will lose access to much of that information after graduation. Information privilege outreach recognizes this while furthering our libraries' information literacy goals. Most important, information privilege outreach reminds us that we must work alongside our students to make our world more open and equitable.

\section{Notes}

1. Association of College \& Research Libraries, "Framework for Information Literacy for Higher Education," available online at www.ala.org/acrl/standards/ilframework [accessed 1 September 2017].

2. Benjamin Harris, "Encountering Values: The Place of Critical Consciousness in the Competency Standards," in Critical Library Instruction: Theories and Methods, eds. Maria T. Accardi, Emily Drabinski, and Alana Kumbier (Duluth, Minn.: Library Juice Press, 2010), 279.

3. Annie Downey, Critical Information Literacy (Sacramento, Calif.: Library Juice Press, 2016), 41.

4. Downey, Critical Information Literacy, 86.

5. James Elmborg, "Critical Information Literacy: Implications for Instructional Practice," Journal of Academic Librarianship 32, no. 2 (2006): 193.

6. Ibid.

7. Ibid.

8. Ibid.

9. Eamon Tewell, "A Decade of Critical Information Literacy: A Review of the Literature," Communications in Information Literacy 9, no. 1 (2015): 25.

10. Christine Pawley, “Information Literacy: A Contradictory Coupling," Library Quarterly 73, no. 4 (2003): 448.

11. Char Booth, "open access as pedagogy," info-mational (blog, July 29, 2013), available online at https://infomational.wordpress.com/2013/07/29/open-access-as-pedagogy/ [accessed 1 October 2017].

12. Ibid.

13. Ibid.

14. Char Booth, "on information privilege," info-mational (blog, Dec. 1, 2014), available online at https://infomational.wordpress.com/2014/12/01/on-information-privilege/ [accessed 1 October 2017].

15. Ibid.

16. Eryk Salvaggio, "Information Privilege and Wikipedia: A Conversation with Char Booth (Part 1)," WikiEdu (blog, Feb. 2, 2015), available online at https://wikiedu.org/blog/2015/02/02/ char-booth-wikipedia-1/ [accessed 1 October 2017]; Eryk Salvaggio, "Learning through Wikipedia: A Conversation with Char Booth (Part 2)," WikiEdu (blog, Feb. 4, 2015), available online at http:// wikiedu.org/blog/2015/02/04/char-booth-wikipedia-2/ [accessed 1 October 2017]; Char Booth, "Information Privilege: Critical Approaches to Access and Advocacy" (presentation, Digital Library Federation Forum, Austin, TX, November 4-6, 2013), available online at http://mediasite.engr. utexas.edu/UTMediasite/Play/15fef35f23364ca0bbe4f0ee5f04a3e71d [accessed 1 October 2017].

17. Char Booth, "on information privilege."

18. Ibid.

19. Char Booth, "open access as pedagogy"; Char Booth, "Information Privilege: Critical Approaches to Access and Advocacy."

20. Roger Schonfeld, "Maintaining Relationships with Readers as They Cross Affiliations," The Scholarly Kitchen (blog, May 6, 2015), available online at https://scholarlykitchen.sspnet. org/2015/05/06/crossing-affiliations/ [accessed 1 October 2017].

21. Alison Head, "Staying Smart: How Today's Graduates Continue to Learn Once They Complete College," Project Information Literacy (2016), available online at www.projectinfolit.org/ uploads/2/7/5/4/27541717/staying_smart_pil_1_5_2016b_fullreport.pdf [accessed 1 October 2017]. 
22. Ibid.

23. ACRL, "Framework for Information Literacy for Higher Education."

24. Association of College \& Research Libraries Working Group on Intersections of Scholarly Communication and Information Literacy, Intersections of Scholarly Communication and Information Literacy: Creating Strategic Collaborations for a Changing Academic Environment (Chicago, Ill.: Association of College and Research Libraries, 2013), 15.

25. Char Booth, "open access as pedagogy."

26. Char Booth, "on information privilege."

27. Heidi Jacobs, "Information Literacy and Reflective Pedagogical Praxis," Journal of Academic Librarianship 34, no. 3 (2008): 261.

28. National Center for Education Statistics, Davidson College (2016), available online at http:// nces.ed.gov/globallocator/col_info_popup.asp?ID=198385 [accessed 1 October 2017].

29. Davidson College, "The Davidson Trust," available online at www.davidson.edu/about/ distinctly-davidson/the-davidson-trust [accessed 1 September 2017].

30. Davidson College, "Distinctly Davidson," available online at https://www.davidson.edu/ about/distinctly-davidson [accessed 1 September 2017].

31. Davidson College Center for Career Development, “2015 First Destination Report," SlideShare (last modified Apr. 19, 2016), slide 3, available online at https://www.slideshare.net/ DavidsonCareerDevelopment/2015-first-destination-report/1 [accessed 1 October 2017].

32. Alison Head, "Staying Smart," 4.

33. Ibid., 12.

34. Ibid., 11.

35. Ibid., 4.

36. Davidson College, "Research at Davidson," available online at www.davidson.edu/academics/research [accessed 1 September 2017].

37. For a more extensive discussion of students' misconceptions about Google Scholar, see Scott Warren and Kim Duckett, "“Why Does Google Scholar Sometimes Ask for Money?' Engaging Science Students in Scholarly Communication and the Economics of Information," Journal of Library Administration 50, no. 4 (2010): 349-72.

38. Davidson College, "Vann Center for Ethics," Wayback Machine, available online at accessed September 1, 2017, https://web.archive.org/web/20161225213040/https://www.davidson.edu/offices/vann-center-for-ethics [accessed 1 September 2017].

39. Aaron Swartz, "Guerilla Open Access Manifesto" (last modified July 2008), available online at https://archive.org/stream/GuerillaOpenAccessManifesto/Goamjuly2008_djvu.txt [accessed 1 October 2017].

40. "Addendum to Publication Agreement," SPARC (last modified 2017), available online at https://sparcopen.org/our-work/author-rights/brochure-html/ [accessed 1 October 2017].

41. Stephanie Davis-Kahl, "Engaging Undergraduates in Scholarly Communications: Outreach, Education and Advocacy," College E Research Libraries News 73 no. 4 (2012): 213.

42. Questbridge, "About" (last modified 2016), available online at https://www.questbridge. org/about [accessed 1 October 2017].

43. Madeline Newton Driscoll, "Pathways of Privilege," Her Campus (blog, Apr. 4, 2016), available online at https://www.hercampus.com/school/davidson/pathways-privilege [accessed 1 October 2017]. 